\title{
Experimental and numerical investigation of novel partially connected steel plate shear walls
}

\author{
Mu-Wang Wei ${ }^{1,2}$, J Y Richard Liew*2,3, Du Yong ${ }^{3}$, and Xue-Yi Fu' ${ }^{1}$
}

\begin{abstract}
A steel plate shear wall system, consisting of a thin steel plate connected to the boundary frame members, is proposed as lateral load resisting system for use in the multi-storey building. To reduce the potential damage on the boundary elements caused by the tension field action in the steel plate after buckling, the steel plate is partially connected at the corner edges to the boundary frame members by bolts. Two scaled specimens were tested under cyclic loads to investigate the hysteretic behaviour of the partially connected steel plate shear wall (SPSW). Test results showed that the proposed SPSW exhibited good structural performance in terms of initial stiffness, shear resistance, ductility and energy absorption capability. An analytical method was developed to predict the shear resistance of the partially connected SPSW. The shear resistances obtained from the tests were compared with those predicted by the analytical method and a reasonable agreement was observed. In addition, a nonlinear finite element (FE) model was proposed to analyze the behaviour of the partially connected SPSW system. The accuracy of the FE models was verified by comparing the computed results with the cyclic load test results. Parametric analyses were then carried out to study the effects of plate slenderness ratio, plate
\end{abstract}


aspect ratio (width/height), stiffness of the boundary frame members and initial plate imperfection on the lateral load resisting behaviour of the proposed steel plate shear wall system. Keywords: cyclic test; partial connection; steel plate shear wall; shear resistance; hysteretic behaviour

\section{Introduction}

Steel plate shear wall (SPSW) has been proposed as a robust and efficient lateral load resisting system in high seismic countries such as North America and Japan [1]. In the past years, experimental and numerical investigations have been widely performed on the SPSW systems [2-8]. It has been demonstrated that the SPSW has better performance on ductility, initial stiffness, shear resistance and energy absorption than the conventional reinforced concrete shear wall. Thorburn et al. [4] reported that the more rigid were the vertical boundary elements (VBEs), the more efficient was the tension field of steel plate in resisting the lateral force. Based on force equilibrium, the tension field developed in the steel plate will be resisted by the boundary frame elements which consist of horizontal boundary elements (HBEs) and vertical boundary element (VBEs). A full tension field action can only be formed if it can be anchored by the rigid boundary elements. ANSI/AISC 341-10 [9] recommends that the VBEs shall have a moment of inertia about the axis perpendicular to the plane of its web not less than $0.00307 \mathrm{th}^{4} / \mathrm{L}$, where $t, h$, and $L$ are the thickness, height, and width of the steel plate, respectively. This is to allow for a full-yield zone to be developed in the tension region of the steel plate. As a result of this, large member size is generally required for the VBEs to satisfy the stiffness requirement and 
this implies more cost for the SPSW system. Set against this background, many types of SPSWs with various structural configurations have been proposed to reduce the stiffness requirement on the VBEs [10-15].

In this paper, a novel partially connected SPSW system is proposed, as shown in Fig. 1, with an aim to reduce the tension force acting on the boundary elements. The partially connected SPSW system comprises of a thin steel plate which is bolted connected at the four-corner edges to the horizontal boundary elements (HBEs) and the vertical boundary elements (VBEs) using equal angle sections and gusset plates. The main novelty of this system is that only the quarter height and width of the steel plate at the four corners are bolted to the boundary elements (HBEs and VEBs) by the gusset plates and equal angle plates, whereas the corresponding mid portions of the plate are not connected to the boundary elements. The advantages of using the proposed partially connected SPSW to resist lateral loads are:

(1) Smaller tension field action shall be developed in the steel plate and less force will be acting on the VBEs after the steel plate buckled. The partially connected SPSWs have lower stiffness demands for the VBEs [16];

(2) The tension field action in the steel plate would be directly transferred to the boundary elements via the beam-column joints as shown in Fig. 2. Thus, the proposed structural system greatly meets the requirement for seismic design for strong joint and weak member framing.

(3) The steel plate can be seen as a "fuse" in the system. The yield strength of the steel plate is designed to be lower than the frame members (HBEs and VBEs) so that the steel plate participates as an energy dissipation device due to the reversal loads, and thus preventing major damage in the structural framework. 
(4) The steel plate is connected to the boundary elements by bolts. Hence, the assembled structural system is convenient to construct, transport and maintain with relatively lower cost than the traditional reinforced concrete shear wall system.

In this paper, two one-third scaled test specimens were prepared and tested under quasistatic cyclic loads to investigate their hysteretic behaviours. An analytical method was developed to predict the shear resistance of the partially connected SPSW. In addition, a nonlinear finite element (FE) model was developed to predict its lateral load displacement behaviour. The accuracies of the analytical method and the FE model were verified by comparing the predicted results with the cyclic load test results. Based on the validated FE model, an extensive parametric study was carried out to examine the influence of plate slenderness ratio, aspect ratio (width/ height), stiffness of VBEs, and initial geometric imperfection on the behaviour of the partially connected SPSW system.

\section{Experimental programs}

\subsection{Test specimens}

Two one-third scaled one-bay one-story specimens were fabricated and tested under quasistatic cyclic load in the structural engineering laboratory at the Nanjing Tech University of China. In addition to the primary objective, which is to study the seismic performance of the partially connected SPSW, the tests also investigate the effect of the plate slenderness ratio on the seismic behaviour of the partially connected SPSW. The steel plate thickness adopted in specimen SPSW1 is $2.3 \mathrm{~mm}$, and specimen SPSW2 is $3.2 \mathrm{~mm}$. The size of the infill plates is $1002 \times 1002 \mathrm{~mm}$. The details of the test specimens are given Table 1 . The specimens have an 
overall height of $1624 \mathrm{~mm}$ and an overall width of $1924 \mathrm{~mm}$. The detailed dimension and configuration of the specimens are shown in Fig. 3 and Fig. 4. To eliminate the lateral load resistance contributed by the moment resistance frame, the beam-to-column joints are designed as pin-jointed as shown in Fig. 3. A single M60 grade 8.8 bolts is used to provide the hinged connection between the HBE and VBE. According to the AISC 341-10 [9] and AISC Design Guide 20 [17], the stiffness of the boundary elements (HBEs and VBEs) shall be designed to allow for full yield zone to be developed across the diagonal area of the infill steel plate. The cross-section for HBEs and VBEs are H-312×310 $\times 21 \times 20 \mathrm{~mm}(\mathrm{H}-$ overall depth $\times$ flange width $\times$ web thickness $\times$ flange thickness). The quarter height and width of the infill steel plate are bolted to boundary elements by equal angle sections and gusset plates. M12 grade 8.8 bolts with a center-to-center distance of $36 \mathrm{~mm}$ are used for the connections. The angle section is $50 \times 50 \times 5 \mathrm{~mm}($ depth $\times$ width $\times$ thickness $)$ and the gusset plate thickness is $10 \mathrm{~mm}$.

\subsection{Test setup}

The test specimens are mounted on a strong foundation floor using M100 grade 8.8 bolts. The bottom H-beam (HBE) is prevented from moving horizontally by using two jacks positioned at the two ends of the bottom HBE. A later load is applied at the top of the specimen by a servo controlled hydraulic actuator mounted between the specimen and a strong reaction wall. The detailed test setup is shown in Fig. 5.

\subsection{Instrumentation}


A load cell is mounted on the hydraulic actuator to monitor the lateral loads applied to the specimen. Several linear variable differential transducers (LVDTs) are used to measure the displacements and their locations are shown in Fig. 5. LVDT 1 measures the lateral displacement at the top HBE of the specimen. LVDT 2 and LVDT 3 monitor the lateral displacement of VBE along the height of specimen. LVDT 4 and LVDT 5 monitor the rotation caused by a possible uplift of the bottom HBE from the strong floor during testing. The out-of-plane twisting of the specimen is measured by LVDT 6 and LVDT 7 mounted at the top HBE ends. In addition, a control and data acquisition system is also used to control the displacement of the actuator and collect the data from the LVDTs.

\subsection{Initial imperfection of steel plate}

The initial geometric imperfection of the infill steel plate would affect the buckling behaviour of the SPSW, therefore, the plate's initial out-of-plane deflection was measured carefully using a laser scanner prior to the test. For specimen SPSW1 and SPWS2, the initial maximum out-of-plane displacement of the infill steel plate was measured as $0.5 \mathrm{~mm}$ and $0.8 \mathrm{~mm}$, which were about $1 / 500$ and 1/800 of steel plate height, respectively. They met the requirement given in GB 50205-2001[18] that the initial out-of-plane imperfection should not be more than 1.5/1000 the plate's height. The effect of plate's initial imperfection would be further studied using the nonlinear finite element analyses hereinafter.

2.5 Loading procedure 
According to the Chinese Specification of Testing Methods for Earthquake Resistant Building (JGJ101-96) [19], the procedure of lateral cyclic loading for the tests is illustrated in Fig. 6. The lateral loading firstly is force-controlled and one cycle is performed at each force level prior to the yielding of the specimen. Three force levels at $1 / 3,2 / 3$ and 1.0 the predicted yield load of the test specimen are applied in the force-controlled phase. After the specimen yielded, the loading procedure is replaced by a displacement control method. The horizontal displacement at the top HBE is expressed in terms of the drift ratio $\theta$, which is defined as the ratio of the lateral displacement against the height of the specimen. The target drift ratio is of $4 \%$ which is the ultimate rotation of the test specimens. As the predicted yield drift ratio $\theta_{y}$ is approximately $0.3 \%$, the lateral drift ratios increase in the sequence of $0.3 \%\left(\theta_{y}\right), 0.6 \%\left(2 \theta_{y}\right)$ $1.2 \%\left(4 \theta_{y}\right), 1.8 \%\left(6 \theta_{y}\right), 2.4 \%\left(8 \theta_{y}\right), 3.0 \%\left(10 \theta_{y}\right), 3.6 \%\left(12 \theta_{y}\right)$ and $4 \%\left(13.3 \theta_{y}\right)$. Three cycles are repeated at each drift ratio level. In each loading cycle, a pushing force is applied firstly and then followed by a pulling force, where the pushing force is defined as the positive loading and the pulling force is defined as the negative loading. The test is terminated while the limit rotation was achieved where the drift ratio is $4 \%$.

\subsection{Material tests}

The infill steel plates in the test specimens are made of Q235. Three steel coupons were prepared from each steel plate and tensile tests were conducted to obtain the mechanical properties of the steel plates. The average yield stresses of the plates are $210 \mathrm{MPa}$ and $223 \mathrm{MPa}$ for specimens SPSW1 and SPSW2, respectively. The average thicknesses of the infill steel plates for SPSW1 and SPSW2 are $2.38 \mathrm{~mm}$ and $3.20 \mathrm{~mm}$, respectively. Meanwhile, the steel grade for 
HBEs and VBEs are specified to be Q345 with nominal yield strength, $f_{y}$, of $345 \mathrm{Mpa}$. As the boundary elements (HBEs and VBEs) are expected to remain elastic after the yielding of the infill steel plate, coupon tests on the boundary frame members are not performed. All the bolts used in the test specimen have a strength grade of 8.8 , where the nominal ultimate strength, $f_{u}$, and yield strength, $f_{y}$, are assumed to be $800 \mathrm{MPa}$ and $640 \mathrm{MPa}$, respectively. Detailed information of the test specimens is summarized in Table 2.

\section{Discussions of results}

\subsection{Elastic stiffness and shear resistance}

The hysteretic behaviour characterized by the relationship between the applied lateral force versus the lateral displacement at the top of the specimen is shown in Fig. 7. It can be seen that the proposed partially connected SPSW specimens exhibit good performance in terms of initial stiffness, ultimate strength, ductility, and energy dissipation. The specimens show stable cyclic behaviour along with somewhat pinching that is mainly attributed to the occurrence of buckling in the infill steel plate. The deformed shapes of the test specimens at the peak of the $25^{\text {th }}$ cycle are shown in Fig. 8. The infill steel plates had buckled into about four half-waves with an inclination angle of approximately 45 degrees. It is also noted that both specimen SPSW1 and SPSW2 show some nonlinear material behaviour at the drift ratio level of about $0.28 \%(1 \mathrm{~mm})$ where the infill steel plate has yielded in the tension field. At this point, the hysteresis loops were significantly opened and the peak force was about $156 \mathrm{kN}$ and $250 \mathrm{kN}$, respectively. Meanwhile, a noticeable buckling deformation was also observed. As an increase in a drift ratio up to $4 \%$ $(40 \mathrm{~mm})$ which is the limit rotation of the hinged frame, a peak load of $249 \mathrm{kN}$ and $313 \mathrm{kN}$ was 
achieved for specimen SPSW1 and SPSW2, respectively. The peak values are treated as the system's maximum resistance. After that, the hinged frame was seemed to be changed to a semihinged frame and participated in resisting the applied load as shown in Fig. 9. Thus, the tests were terminated at this cycle level.

A summary of the specimens' response at different cycle level is presented in Table 3 . In addition, the initial stiffness, yield point, ultimate load and maximum displacement of the test specimen are given in Table 4. Meanwhile, the envelope curves of the load versus displacement are compared in Fig. 10 where these curves were developed by plotting the points with the peak displacement of each cycle level and corresponding applied force. It is noted from the curves that the slenderness ratio of the infill steel plate has a significant effect on the initial stiffness and the shear resistance of the proposed system. As the infill panel thickness is increased from $2.38 \mathrm{~mm}$ (SPSW1) to $3.20 \mathrm{~mm}$ (SPSW2), the initial stiffness is observed to increase by 1.6 times. The maximum resistance of specimen SPSW2 with thicker infill panel is approximately 1.6 times higher than SPSW1.

\subsection{Ductility}

The test results show that the proposed system has good ductility. According to the definition in the AISC [9], the ductility factor, $\mu$, can be expressed as:

$$
\mu=\frac{u_{t}}{u_{y}}
$$


where, $u_{t}$ is the maximum displacement that can be obtained through the tests; $u_{y}$ is the idealized yield displacement. The idealized yield point is defined by the principle of energy conservation as shown in Fig. 11 where the area enclosed by the idealized elastoplastic envelope curve is equal to that enclosed by the actual envelope curve. The ductility factors of the specimens are

listed in Table 4. It is noted that the ductility factor of the partially connected SPSWs has exceeded 13.0. Therefore, the proposed system has good ductility performance.

\subsection{Energy dissipation capacity}

The amount of energy dissipation is considered as an important factor in seismic design. The cumulative energy dissipation of the specimens at per cycle level is presented in Fig. 12. The energy dissipation is calculated using the average area enclosed by the three complete loaddisplacement cycle curve at each displacement level. The energy dissipated by specimen SPSW1 and SPSW2 are nearly identical until the drift ratio cycle level up to about $0.28 \%(2.8 \mathrm{~mm})$. After that, the energy dissipation by SPSW2 is seemed to exceed that of SPSW1 by a factor of approximately 1.2 at the $4 \%$ drift ratio cycle level. In addition, it can be further seen from Fig. 13 that the energy dissipated by specimen SPSW2 with thicker infill panel is greater than specimen SPSW1 with thinner infill plate. Therefore, the thickness of infill steel plate is an important parameter that affects the energy dissipation of the partially connected SPSW.

\section{Shear resistances}

4.1 Thorburn and AISC methods 
A method was originally developed by Thorburn et al. [4] to predict the shear resistance of full connected SPSW. They proposed to replace the tension zone of the steel plate with an equivalent truss element having the same story stiffness. The equation determining the shearing yield force, $V_{n}$, of the equivalent truss model is written as:

$V_{n}=f_{y} A \sin \phi$

where, $f_{y}$ is the yield strength of steel plate; $A$ is the cross-section area of an equivalent truss member expressed as

$$
A=\frac{t L \sin ^{2} 2 \alpha}{2 \sin \phi \sin 2 \phi}
$$

where, $L$ is the width of infill panel. For the proposed partially connected SPSW, the effective width of steel plate can be considered as the connection length $L / 2 ; t$ is the thickness of steel plate; $\phi$ is the angle between the equivalent truss member and the VBE; $\alpha$ is the angle of inclination of the tension field determined by

$$
\tan ^{4}=\frac{1+\frac{t L}{2 A_{c}}}{1+\operatorname{th}\left(\frac{1}{A_{b}}+\frac{h^{3}}{360 I_{c} L}\right)}
$$

where $I_{c}$ is the second moment of area of the column section; $A_{c}$ and $A_{b}$ are the effective sectional area of VBE and HBE, respectively; $h$ is the height of infill steel plate. In term of the proposed system, the inclination angle is same as the angle between the equivalent truss and the VBE. 
On the other hand, a simpler approach adopted by ANSI/AISC 341-10 [9] to determine the shear strength of full connected SPSW, $V_{n}$, is expressed as $V_{n}=0.42 f_{y} t L \sin 2 \alpha$

where, $f_{y}$ is the yield strength of the steel plate. $t$ is the thickness of the steel plate. $L$ is the width of the steel plate. The angle of inclination, $\alpha$, is permitted to be taken as $40^{\circ}$ or calculated by Eq. (4).

\subsection{Proposed modified method}

It should be noted that the current methods for determining the shear resistance of the full connected SPSW only consider the effect of the tension field. The contribution of compression stress in the orthogonal direction is generally neglected. Thus, in the present study, a modified method with the consideration of compression stress based on the "equivalent truss model" is proposed to predict the shear resistance of fully or partially connected SPSW. The proposed approach is calculated based on the following assumptions:

(1) To eliminate the effect of the surrounding boundary elements (HBEs and VBEs), the HBEs are assumed to be hinged to the VBEs.

(2) The flexural stiffness of the boundary elements (HBEs and VBEs) is considered to be sufficient to ensure that the yielding zone across the entire steel plate.

When a horizontal shearing force, $V$, is applied to the SPSW, the bending stresses acting on the steel plate can be neglected. The resulting shear stress on the edges of steel plate is assumed to be $\sigma_{v}$. Prior to buckling, the steel plate is subjected to pure shear. As it is a state of pure shear, 
the shear stress is equivalent to two principal stresses of equal magnitude. One is tension, $\sigma_{t}$, and the other is compression, $\sigma_{c}$, inclined at $45^{\circ}$ to the shear stress. With the increasing shearing force, the shear stress continues to increase correspondingly until the shear buckling stress of the steel plate is reached. For a fully connected SPSW, an equation has been proposed to determine the stress at which shear buckling develops in a steel plate by Timoshenko [20] as

$\sigma_{v, b}=\frac{\pi^{2} E}{12\left(1-v^{2}\right)}\left(\frac{t}{h}\right)^{2} k$

where, $v$ is the Poisson's ratio of steel material; $k$ is the plate factor dependent on the boundary conditions of the steel plate [19]. Since the steel plate is bolted to the boundary elements (HBEs and VBEs), the support condition can be assumed as simply supported condition. The plate factor, $k$, can be expressed as

$k=\left\{\begin{array}{l}5.34+4(h / L)^{2}, h / L>1 \\ 4+5.34(h / L)^{2}, h / L \leq 1\end{array}\right.$

On the other hand, if the steel plate is connected to the boundary elements (HBEs and VBEs) by welding, the support condition is similar to a fixed support. The plate factor, $k$, is rewritten as $k=\left\{\begin{array}{l}8.98+5.60(h / L)^{2}, h / L>1 \\ 5.60+8.98(h / L)^{2}, h / L \leq 1\end{array}\right.$

In addition, for the proposed partially connected SPSW, the compression field of steel plate in the diagonal area is treated as a rectangular plate with width, $a$, and height, $b$, under 
compression force along the " $b$ " edge, as shown in Fig. 13. When a lateral force, $V$, is applied to the frame, low-order buckling develops in the equivalent rectangular plate with $m$ buckling halfwavelength. The buckling stress, $\sigma_{c, b}$, can be obtained as [20]

$\sigma_{c, b}=\frac{\pi^{2} E}{12\left(1-v^{2}\right)}\left(\frac{t}{b}\right)^{2}\left(\frac{m b}{a}+\frac{a}{m b}\right)^{2}$

in which, four buckling half-waves can be generally observed in the test results. As a result, the number of the buckling half-waves, $m$, can be assumed to be 4 .

After buckling, the buckled deformation will further develop in the direction of the diagonal compression zone. Consequently, the compressive principal stress cannot increase any further. However, the tension principal stress is limited only by the strength of the steel plate, and it will continue to increase in response to the increasing shearing force after the buckling deformation forms in the steel plate until the yield strength level. Based on the equivalent truss model as described previously, a mechanical equilibrium which is developed to determine the shear resistance considering the effect of compression truss, as illustrated in Fig. 14, is given $V_{n}=\left(\sigma_{t}+\sigma_{c}\right) A \cos \phi$

where, it should be noted that for fully connected SPSW, $\sigma_{c}$ is equivalent to the shear buckling stress, $\sigma_{v, b}$, expressed by Eq. (6), whereas, for the proposed partially connected SPSW, $\sigma_{c}$ should be replaced with $\sigma_{c, b}$ in Eq. (9).

The test results from literature [21-23] and this paper are employed to establish the validation of the prediction of shear resistance using the above three methods. The shear resistances are compared in Table 5. It can be seen that both Thorburn and AISC method 
significantly underestimate the shear resistance of SPSW. However, owing to the consideration of the contribution of the compression in the orthogonal direction, the proposed modified method can predict the shear resistance more accurately than the other two methods.

\section{Nonlinear finite element analyses}

The SPSW test specimens presented in the literature and in the present paper come with specific dimensions and parameters which do not cover the full range of cases that might be encountered in practice. It is, therefore, necessary to develop a numerical model to investigate the behaviour of partially connected SPSW with different geometry, avoiding a large expense of conducting additional tests. Thus, a reliable FE model is developed herein to simulate the behaviour of the proposed SPSW subjected to cyclic loading. Meanwhile, the FE model will be validated using the test results so that it can be used to further analyze the other partially connected SPSW with different configurations.

\subsection{Finite element model}

The commercial software ABAQUS 14.1[24] is adopted to model the nonlinear behaviour of the partially connected SPSWs subjected to monotonic and cyclic loading. The FE models of partially connected SPSWs are designed with a full storey height, $h$, of $3000 \mathrm{~mm}$, as shown in Fig. 15. The pin-jointed frame with $\mathrm{H}-$ section is employed in the FE models so that the contribution of boundary elements can be excluded. The "hinge" element is used to simulate the hinge joint behaviour. The connection members, including equal angle steel plates and gusset plates, used in test specimens to connect the infill steel plate to the boundary elements are not 
considered in the FE models. The effects of this approximation were found to be small and can be neglected [7]. Therefore, the infill steel plate is considered to be tied directly to the boundary elements (HBEs and VBEs) at four corners whereas the mid-width/height of the steel plate is not connected to the boundary elements, as shown in Fig. 15. The support condition at the bottom HBE is assumed to be a fixed-end condition by restraining the six degrees of freedom. The lateral load is applied uniformly at the end of top HBE. In addition, the plate's initial imperfection should be considered prior to the FE analysis. For comparison with test results, the actual measured plate imperfections should be used. As for the pattern of imperfection, the first buckling mode of the infill steel plate may be used, obtained from an eigenvalue buckling analysis of the shear wall system.

In the present study, a series of FE models are built to investigate the influence of slenderness ratio, aspect ratio, stiffness of VBEs and initial imperfection on the shear resistance and hysteretic behaviour. The details of FE models with different structural parameters are listed in Table 6.

\subsection{Material properties}

The isotropic elastoplastic constitutive behaviour is adopted to simulate the steel material in the test specimens. The properties are identical in tension and compression and the von Mises yield surface is used as the yield criterion. Because of repeated loading and unloading, the kinematic hardening rule is invoked to simulate the Bauschinger effect in the cyclic runs. The stress-strain relation of infill steel plate measured from coupon tests with a bilinear representation is employed to describe steel plate properties, as shown in Fig.16. The bilinear 
stress-strain curve extends from the origin to the mean value of the measured yield point and the slope is considered to be the mean modulus of elasticity. After yield point, the stress is assumed to linearly increase until the plastic strain is reached at 0.1 .

\subsection{Element type and mesh sensitively}

HBEs, VBEs, and infill steel plates are modeled using four-node shell elements S4R with reduced integration. This element has six degrees of freedom per node. As the rotational degrees of freedom are described independently from the translational degrees of freedom, transverse shear deformation of the cross section is automatically taken into account. Therefore, the Kirchhoff shear constraints are released. The spatial strain field distribution is sampled at four Gaussian integration points located on the mid-surface. At each Gauss point, the flexural behaviour of the shell element is numerically integrated across five integration points through the thickness. This accurately describes the nonlinear behaviour across the thickness of the infill steel plates. In addition, according to the preliminary FE analysis, the FE models with mesh refinement $50 \mathrm{~mm} \times 50 \mathrm{~mm}$ have a reasonable agreement with the test result. Therefore, in this paper, $50 \mathrm{~mm} \times 50 \mathrm{~mm}$ element is finally adopted in FE models to perform further case study hereinafter.

\subsection{ABAQUS solver}

Implicit and explicit solvers are applicable to perform the nonlinear analysis in ABAQUS [24]. It is acknowledged that ABAQUS/implicit analysis is frequently terminated mainly contributed to the convergence problem primarily caused by excessive contacting pairs, large 
deformation, and complicated nonlinear behaviour. However, the explicit solver can be employed to overcome the challenges as the time increment is controlled reasonably for a quasistatic analysis. Therefore, in the present study, ABAQUS/explicit solver is adopted to conduct further FE analyses. Furthermore, to acquire reliable quasi-static solutions using the explicit solver, loading rate should be sufficiently slow. In this way, the excessive kinematic energy can be avoided. Various loading rates have been tested before FE analysis and the reasonable rate is found to be approximately $1 \mathrm{~mm} / \mathrm{s}$ for numerical simulation.

\subsection{Verification of FE models against test results}

The experimental works described in section 3 are used to verify the proposed FE models. The test and FE results are compared in Fig.17. It can be seen that the proposed FE models can reasonably predict the shear resistance, overall hysteretic responses and envelope curves of test specimens. It is also noted that the predicted curves show slightly higher stiffness. Nevertheless, a good fit is generally observed. Thus, based on the validated FE models, an extensive parametric study can be performed to investigate the effect of slenderness ratio, aspect ratio (width/height), stiffness of VBEs, and initial imperfection on the behaviour of the partially connected SPSWs.

5.6 Parametric studies on partially connected SPSW

\subsubsection{Effect of slenderness ratio of infill steel plate}

Three FE models of the partially connected SPSWs are built to investigate the effect of slenderness ratio, $\lambda,(200,400$ and 600$)$ on the shear resistance and hysteretic behaviour in this 
section. The characteristics of the FE models are shown in Table 6 series 1. It can be seen from Fig. 18 that the shear resistance generally increases by $56 \%$ and $252 \%$ as the slenderness ratio decreases from 600 to 200 with an interval of 200. Moreover, the lateral stiffness of the shear wall system significantly becomes stiffer with the reduced slenderness ratio. The reason is that as the slenderness ratio is decreased from 600 to 200 , the thickness of the infill steel plate is gradually increased from $5 \mathrm{~mm}$ to $15 \mathrm{~mm}$. And as described in Eq. (10), the shear resistance of partially connected SPSWs greatly depends on the plate thickness. In addition, the amount of dissipated energy measured from the area enclosed by the hysteresis loop is distinctly increased as the slenderness ratio is decreased. It is also noted that the hysteretic curves exhibit some pinching as observed in test specimens. It is attributed to that the out-of-plane buckling deformation, $\Delta_{\text {out, }}$ occurs in the infill steel plate, as shown in Fig. 19. Furthermore, it can be seen that the maximum out-of-plane displacement at the center of the infill steel plate is increased from $61.6 \mathrm{~mm}$ to $66.5 \mathrm{~mm}$ as the slenderness ratio is decreased from 600 to 200 . It is due to the fact that as the steel plate is thickened, its flexural stiffness in the out-of-plane is enhanced.

\subsubsection{Effect of aspect ratio}

In order to assess the effect of aspect ratio, $L / h$, on the cyclic behaviour of the partially connected SPSWs, the hysteretic analysis is conducted with different $L / h$. Keeping the slenderness ratio, $\lambda$, constant as 400 , the influence of a change in $L / h(1,1.5$ and 2$)$ is examined. Figure 20 illustrates that as the aspect ratio is increased from 1.0 to 1.5 and 2.0, the shear resistance correspondingly increases by $35.3 \%$ and $74.4 \%$. That is mainly attributed to that the

shear resistance of the partially connected SPSWs is greatly related to the angle, ${ }^{\phi}$, as described 
in Eq. (10). The infill steel plate is widened as the $L / h$ increases while its height remains unchanged and the angle, ${ }^{\phi}$, decreases as the infill steel panel is widened with a given height. Meanwhile, it is also found that the lateral initial stiffness of shear wall system is increased with the increasing aspect ratio. In addition, the hysteresis curves show that the energy dissipation capacity is significantly enhanced as the aspect ratio is gradually increased. Therefore, it is believed that the aspect ratio significantly affects the behaviour of the proposed system.

\subsubsection{Effect of stiffness of boundary elements}

The stiffness of the VBE can affect the seismic performance of SPSW. The reason is that a more flexible VBE will experience more inward bending as a result of the horizontal components of the tension field forces. Moreover, flexible VBE generally results in a less efficient distribution of the stresses in the tension field. Thus, in terms of full connected SPSW, to allow for full yielding across the entire infill plate, the American code ANSI/AISC 341-10 [9] requires the VBEs to have a minimum moment of inertia about an axis normal to the plane of its web, $I_{c}$, defined as

$$
I_{c}=\frac{0.00307 t h^{4}}{L}
$$

where, $t, L$ and $h$ are the thickness, width and height of the steel plate respectively.

In order to examine the effect of VBE stiffness on the behaviour of partially connected SPSW, a series of FE models are built with a different moment of inertia. The characteristics of the FE models are shown in Table 6 Series 3. Figure 21 shows that as the moment of inertia is 
increased, the shear resistance steadily increases. Upon the minimum moment of inertia, the shear resistance is converged to a constant value. Meanwhile, it can be seen from the sketch that the partially connected SPSWs require less stiffness than the requirement in AISC [9] for the full connected SPSWs. Therefore, it is deemed that the proposed SPSWs significantly reduce the minimum moment of inertia of VEBs for developing full tension field in the infill steel plate.

\subsubsection{Effect of initial imperfection}

To investigate the effect of the magnitude of the plate's initial imperfections, $\Delta$ imp, on the behaviour of partially connected SPSW, eight different imperfection magnitudes of $0 \mathrm{~mm}(0 \mathrm{~h} /$ 1000), $1 \mathrm{~mm}(0.3 h / 1000), 2 \mathrm{~mm}(0.7 h / 1000), 3 \mathrm{~mm}(h / 1000), 4 \mathrm{~mm}(1.3 h / 1000)$, and 6mm $(2 h /$ 1000) are used in FE modeling. The remaining parameters are kept constant as shown in Table 6

Series 4. The initially buckled deformation for all models is assumed to be the first buckling mode of the infill plate. It can be observed from Fig. 22 that as long as the magnitude of out-ofplane deformation is less than about $3 \mathrm{~mm}(h / 1000)$ the effect is very small and can be neglected. However, while the imperfection magnitude is more than $3 \mathrm{~mm}(h / 1000)$, the stiffness and shear resistance reduction is noticeable and should be accounted for in design. From the above findings, it is recommended that the initial geometric imperfection of the infill panel should be kept within $h / 1000$.

\section{Conclusions}

A novel partially connected SPSW system is proposed to as a lateral load resisting system to dissipate energy due to earthquake loads. Two scaled test specimens are fabricated and tested. An 
analytical method is developed to predict the shear resistance of partially connected SPSW. Nonlinear finite element analysis is also used to investigate the key parameters that have a strong influence on the structural performance of partially connected steel plate shear wall systems. Based on the investigations, the following conclusions can be drawn:

(1) The test results of the partially connected SPSWs exhibit high initial stiffness, adequate ductility, excellent energy absorption capacity and stable hysteresis loop. Therefore, the proposed shear wall system could provide an effective solution to dissipate energy due to reversal wind or earthquake loads.

(2) An analytical method is proposed to predict the shear resistance of partially connected shear wall system. Compared with test results, the proposed method predicts the shear resistance more accurately than the Thorburn and AISC Methods.

(3) The parametric studies conducted using the nonlinear finite element analysis method show that the slenderness ratio of infill panel, aspect ratio of infill panel, and stiffness of vertical boundary elements (VBEs) can have significantly influence on the structural performance of the partially connected SPSWs. The shear resistance and hysteretic behaviour are greatly improved as the aspect ratio of steel plate and the stiffness of VBEs are increased. The lateral load resistance of the SPSWs increases with the decrease of the slenderness ratio of the infill steel plate. In addition, the proposed partially connected SPSW generally require less stiffness demand on the VBEs than the traditional full connected SPSW. In terms of the plate initial out-of-plane deflection, if the magnitude is less than $h / 1000$ the effect is very small and can be neglected. Thus, it is recommended that the initial geometric imperfection of the infill plate should be kept within height/1000. 


\section{Acknowledge}

This experimental work was conducted at the Nanjing Tech University, China. The first author was funded by the China Scholarship Council (CSC) to study at the National University of Singapore. The experimental work was funded by the Chinese National Science Foundation Research Grant No: 51030037.

\section{References}

[1] Astaneh-Asl A. Seismic behaviour and design of steel shear walls. SEOANC Seminar, Structural Engineers Associate of Northern California, 2001, San Francisco.

[2] Kuhn P, Peterson J P and Levin L R. A summary of diagonal tension part ח-experimental evidence. NASA Technical Reports Server, Technical Note 2662, National Advisory Committee for Aeronautics, Washington, 1952.

[3] Takahashi Y, Takemoto Y and Takagi M. "Experimental study on thin steel shear walls and particular bracings under alternative horizontal load", Preliminary Report, IABSE Symposium on Resistance and Ultimate Deformability of Structures Acted on by Welldefined Repeated Loads, Lisbon, Portugal, 1973,185-191.

[4] Thorburn L J, Kulak G L and Montgomery C J. Analysis of steel plate shear walls. Structural Engineering Report, No. 107, Department of Civil Engineering, University of Alberta, Alta, 1983. 
[5] Tromposch E W and Kulak G L. Cyclic and static behaviour of thin panel steel plate shear walls. Structural Engineering Report No.145, Department of Civil Engineering, University of Alberta, Edmonton, 1987

[6] Caccese V, Elgaaly M and Chen R. Experimental study of thin steel-plate shear walls under cyclic load. Journal of Structural Engineering, 1993, 119(2), 573-587.

[7] Driver R G. Seismic behaviour of steel plate shear walls. Dissertation of PH.D., Department of Civil and Environmental engineering, University of Alberta, Alberta, Canada, 1997.

[8] Park H G, Kwack J H, Jeon S W, Kim W K and Choi I P. Framed steel plate wall behaviour under cyclic lateral loading. Journal of Structural Engineering, 2007, 133(3), 378-388.

[9] AISC. Seismic provisions for structural steel buildings. ANSI/AISC 341-10, American Institute of Steel Construction, Chicago, 2010.

[10] Robert T M, Sabouri-Ghomi S. Hysteretic characteristics of unstiffened perforated steel plate shear panels. Thin-walled structure, 1992, 14, 139-151.

[11] Hitaka T, Matsui C and Sakai J I. Cyclic tests on steel and concrete-filled tube frames with slit walls. Earthquake Engineering and Structural Dynamics, 2007, 36(6), 707-727.

[12] Berman J W, Bruneau M. Experimental investigation of light-gauge steel plate shear walls. Journal of Structural Engineering, 2005, 131(2), 259-267.

[13] Berman J W, Celik O C and Bruneau M. Comparing hysteretic behaviour of light-gauge steel plate shear walls and braced frames. Engineering Structures, 2005, 27, 475-485.

[14] Chen SJ, Jhang C. Cyclic behaviour of low yield point steel shear walls. Thin-walled Structure, 2006, 44(7), 730-738. 
[15] Choi I R, Park H G. Steel plate shear walls with various infill plate designs. Journal of Structural Engineering, 2009, 135(7), 785-796.

[16] Wei M W, Liew J Y R and Fu X Y. Panel action of novel partially connected bucklingrestrained steel plate shear walls. Journal of Constructional Steel Research, 2017, 128, 483-497.

[17] AISC. Steel plate shear walls. Steel design guide 20, American Institute of Steel Construction, Chicago, 2007.

[18] GB 50205-2001. Code for acceptance of construction quality of steel structures. Ministry of Housing and Urban-Rural Development of the People's of China, Beijing, 2001.

[19] JGJ101-96. Specification of testing methods for earthquake resistant building. Ministry of Housing and Urban-Rural Development of the People's of China, Beijing, 1996.

[20] Timoshenko S P. Theory of Elastic Stability. McGraw-Hill, New York, 1936.

[21] Roberts T M and Sabouri-Ghomi S. Hysteretic Characteristics of unstiffened perforated steel plate shear panels. Thin-walled Structures, 1992, 14, 139-151.

[22] Valizadeh H, Sheidaii M and Showkati H. Experimental investigation on cyclic behaviour of perforated steel plate shear walls. Journal of Constructional Steel Research, 2012, 70, 308-316.

[23] Guo Y L, Dong Q L and Zhou M. Test and analysis on hysteretic behaviour of bucklingrestrained steel plate shear wall. Journal of Building Structures, 2009, 30(01), 31-47.

[24] ABAQUS. ABACUS user's manual. Version 14.1. Hibbitt, Karlsson, and Sorenson Inc. (HKS), Pawtucket, R. I. 
Table 1 Details of test specimens

\begin{tabular}{ccccccc}
\hline Specimen & $\begin{array}{c}\text { Panel thickness } \\
(t, \mathrm{~mm})\end{array}$ & $\begin{array}{c}\text { Slenderness } \\
(\lambda=h / t)\end{array}$ & $\begin{array}{c}\text { Length } \\
(L, \mathrm{~mm})\end{array}$ & $\begin{array}{c}\text { Height } \\
(h, \mathrm{~mm})\end{array}$ & $\begin{array}{c}\text { Aspect ratio } \\
(L / h)\end{array}$ & $\begin{array}{c}\text { Connection } \\
\text { type }\end{array}$ \\
\hline SPSW1 & 2.3 & 436 & 1002 & 1002 & 1 & Bolt \\
SPSW2 & 3.2 & 313 & 1002 & 1002 & 1 & Bolt \\
\hline
\end{tabular}

Table 2 Results of coupon tests

\begin{tabular}{|c|c|c|c|c|c|}
\hline \multirow{2}{*}{ Specimen } & \multirow{2}{*}{ Coupons } & \multicolumn{2}{|c|}{ Thickness (mm) } & \multirow{2}{*}{$\begin{array}{l}\text { Yield stress } \\
\text { (MPa) }\end{array}$} & \multirow{2}{*}{$\begin{array}{c}\text { Ultimate stress } \\
(\mathrm{MPa})\end{array}$} \\
\hline & & Nominal & Actual & & \\
\hline \multirow{3}{*}{ SPSW1 } & CT1 & 2.3 & 2.38 & 220 & 453 \\
\hline & $\mathrm{CT} 2$ & 2.3 & 2.36 & 201 & 431 \\
\hline & CT3 & 2.3 & 2.40 & 207 & 423 \\
\hline \multirow{5}{*}{ SPSW2 } & Average value & 2.3 & 2.38 & 210 & 436 \\
\hline & CT4 & 3.2 & 3.24 & 213 & 411 \\
\hline & CT5 & 3.2 & 3.14 & 235 & 413 \\
\hline & CT6 & 3.2 & 3.22 & 221 & 418 \\
\hline & Average value & 3.2 & 3.2 & 223 & 414 \\
\hline
\end{tabular}


Table 3 Cyclic test histories

\begin{tabular}{|c|c|c|c|c|c|c|}
\hline $\begin{array}{l}\text { Load } \\
\text { procedure }\end{array}$ & Load step & $\begin{array}{l}\text { Number } \\
\text { of cycles }\end{array}$ & $\begin{array}{c}\text { Cumulative } \\
\text { number of cycles }\end{array}$ & $\begin{array}{c}\text { Peak } \\
\text { load } \\
\left(V_{p}, \mathrm{kN}\right)\end{array}$ & $\begin{array}{l}\text { Displacement } \\
(\Delta, \mathrm{mm})\end{array}$ & $\begin{array}{l}\text { Drift ratio } \\
\quad(\theta, \%)\end{array}$ \\
\hline \multicolumn{7}{|c|}{ SPSW1 } \\
\hline \multirow{3}{*}{$\begin{array}{c}\text { Force } \\
\text { controlled }\end{array}$} & 1 & 1 & 1 & 35 & 0.7 & 0.07 \\
\hline & 2 & 1 & 2 & 75 & 1.4 & 0.14 \\
\hline & 3 & 1 & 3 & 105 & 2.1 & 0.21 \\
\hline \multirow{9}{*}{$\begin{array}{l}\text { Displacement } \\
\text { controlled }\end{array}$} & 1 & 3 & 6 & 156 & 3 & 0.3 \\
\hline & 2 & 3 & 9 & 169 & 6 & 0.6 \\
\hline & 3 & 3 & 12 & 192 & 12 & 1.2 \\
\hline & 4 & 3 & 15 & 224 & 18 & 1.8 \\
\hline & 5 & 3 & 18 & 243 & 24 & 2.4 \\
\hline & 6 & 3 & 21 & 250 & 30 & 3.0 \\
\hline & 7 & 3 & 24 & 258 & 36 & 3.6 \\
\hline & 8 & 3 & 27 & 249 & 40 & 4.0 \\
\hline & 9 & 1 & 27.5 & & & \\
\hline \multicolumn{7}{|c|}{ SPSW2 } \\
\hline \multirow{3}{*}{$\begin{array}{c}\text { Force } \\
\text { controlled }\end{array}$} & 1 & 1 & 1 & 55 & 0.7 & 0.07 \\
\hline & 2 & 1 & 2 & 110 & 1.4 & 0.14 \\
\hline & 3 & 1 & 3 & 165 & 2.1 & 0.21 \\
\hline
\end{tabular}




\begin{tabular}{ccccccc} 
& 1 & 3 & 6 & 250 & 3 & 0.3 \\
& 2 & 3 & 9 & 275 & 6 & 0.6 \\
& 3 & 3 & 12 & 281 & 12 & 1.2 \\
Displacement & 4 & 3 & 15 & 320 & 18 & 1.8 \\
controlled & 5 & 3 & 18 & 336 & 24 & 2.4 \\
& 6 & 3 & 21 & 335 & 30 & 3.0 \\
& 7 & 3 & 24 & 334 & 36 & 3.6 \\
& 8 & 3 & 27 & 331 & 40 & 4.0 \\
\hline
\end{tabular}

Table 4 Hysteretic behaviour of test specimens

\begin{tabular}{ccccccc}
\hline Specimen & $\begin{array}{c}\text { Initial } \\
\text { stiffness } \\
\left(K_{0}, \mathrm{kN} / \mathrm{mm}\right)\end{array}$ & $\begin{array}{c}\text { Yield } \\
\text { load } \\
\left(V_{y}, \mathrm{kN}\right)\end{array}$ & $\begin{array}{c}\text { Yield } \\
\text { displacement } \\
\left(\Delta_{y}, \mathrm{~mm}\right)\end{array}$ & $\begin{array}{c}\text { Ultimate } \\
\text { load } \\
\left(V_{u}, \mathrm{kN}\right)\end{array}$ & $\begin{array}{c}\text { Maximum } \\
\text { drift ratio } \\
\left(\theta_{\max }\right)\end{array}$ & $\begin{array}{c}\text { Ductility } \\
\text { ratio } \\
\left(\Delta_{\max } / \Delta_{y}\right)\end{array}$ \\
\hline SPSW1 & 53.8 & 155.8 & 2.9 & 258 & $4 \%$ & 13.8 \\
SPSW2 & 87.2 & 250.4 & 2.8 & 334 & $4 \%$ & 14.3 \\
\hline
\end{tabular}


Table 5 Comparison of shear resistance between test results and three methods

\begin{tabular}{|c|c|c|c|c|c|c|c|c|c|c|}
\hline \multirow[b]{2}{*}{$\begin{array}{l}\text { Source of } \\
\text { test data }\end{array}$} & \multirow[b]{2}{*}{$\begin{array}{l}\text { Specim } \\
\text { ens }\end{array}$} & \multicolumn{4}{|c|}{ Steel plate } & \multicolumn{4}{|c|}{ Shear resistance $\left(V_{n}, \mathrm{kN}\right)$} & \multirow[b]{2}{*}{$\begin{array}{l}\text { Ratio } \\
\text { (Eq. } \\
(10) / \\
\text { Test) }\end{array}$} \\
\hline & & $\begin{array}{c}\text { Widt } \\
\mathrm{h} \\
(L, \\
\mathrm{mm})\end{array}$ & $\begin{array}{c}\text { Heig } \\
\mathrm{ht} \\
(h, \\
\mathrm{mm})\end{array}$ & $\begin{array}{c}\text { Thick } \\
\text { ness } \\
(t, \\
\mathrm{mm})\end{array}$ & $\begin{array}{c}\text { Yield } \\
\text { stren } \\
\text { gth } \\
\left(f_{y},\right. \\
\mathrm{MPa})\end{array}$ & $\begin{array}{c}\text { Tes } \\
\mathrm{t}\end{array}$ & $\begin{array}{l}\text { Thorb } \\
\text { urn } \\
\text { by Eq. } \\
\text { (2) }\end{array}$ & $\begin{array}{c}\text { AISC } \\
\text { by Eq. } \\
\text { (5) }\end{array}$ & $\begin{array}{c}\text { Predict } \\
\text { ion by } \\
\text { Eq. } \\
(10)\end{array}$ & \\
\hline \multirow{2}{*}{$\begin{array}{c}\text { Valizadeh } \\
\text { H et al } \\
{[21]}\end{array}$} & SPW1 & 500 & 500 & 0.7 & 180 & $\begin{array}{c}36 . \\
7\end{array}$ & 30.5 & 26.1 & 32.5 & 0.89 \\
\hline & SPW5 & 500 & 500 & 0.37 & 300 & $\begin{array}{c}27 . \\
8\end{array}$ & 26.8 & 22.9 & 27.8 & 1.00 \\
\hline \multirow{4}{*}{$\begin{array}{c}\text { Roberts T } \\
\mathrm{M} \text { et al } \\
{[22]}\end{array}$} & Test2 & 300 & 300 & 0.83 & 219 & 33 & 26.4 & 22.5 & 29.0 & 0.89 \\
\hline & Test3 & 300 & 300 & 1.23 & 152 & 40 & 27.2 & 23.2 & 35.5 & 0.89 \\
\hline & Test14 & 450 & 300 & 0.83 & 219 & 60 & 42.9 & 33.8 & 68.2 & 1.13 \\
\hline & Test15 & 450 & 300 & 1.23 & 152 & 70 & 44.1 & 34.8 & 79.2 & 1.13 \\
\hline \multirow{2}{*}{$\begin{array}{c}\text { Guo Y L et } \\
\text { al[23] }\end{array}$} & $\begin{array}{c}\text { SPSW- } \\
500\end{array}$ & 1100 & 1100 & 2.2 & 382 & 470 & 448.3 & 382.4 & 461.3 & 0.98 \\
\hline & $\begin{array}{c}\text { SPSW- } \\
400\end{array}$ & 1100 & 1100 & 2.8 & 324 & 550 & 483.9 & 412.8 & 510.7 & 0.93 \\
\hline \multirow{2}{*}{$\begin{array}{l}\text { Test by } \\
\text { authors }\end{array}$} & $\begin{array}{c}\text { SPSW } \\
1\end{array}$ & 1002 & 1002 & 2.3 & 210 & $\begin{array}{c}155 \\
.8\end{array}$ & 120.8 & 99.8 & 140.8 & 0.90 \\
\hline & $\begin{array}{c}\text { SPSW } \\
2\end{array}$ & 1002 & 1002 & 3.2 & 223 & $\begin{array}{c}250 \\
.4\end{array}$ & 178.4 & 147.6 & 232.3 & 0.93 \\
\hline
\end{tabular}


Table 6 Details of FE model

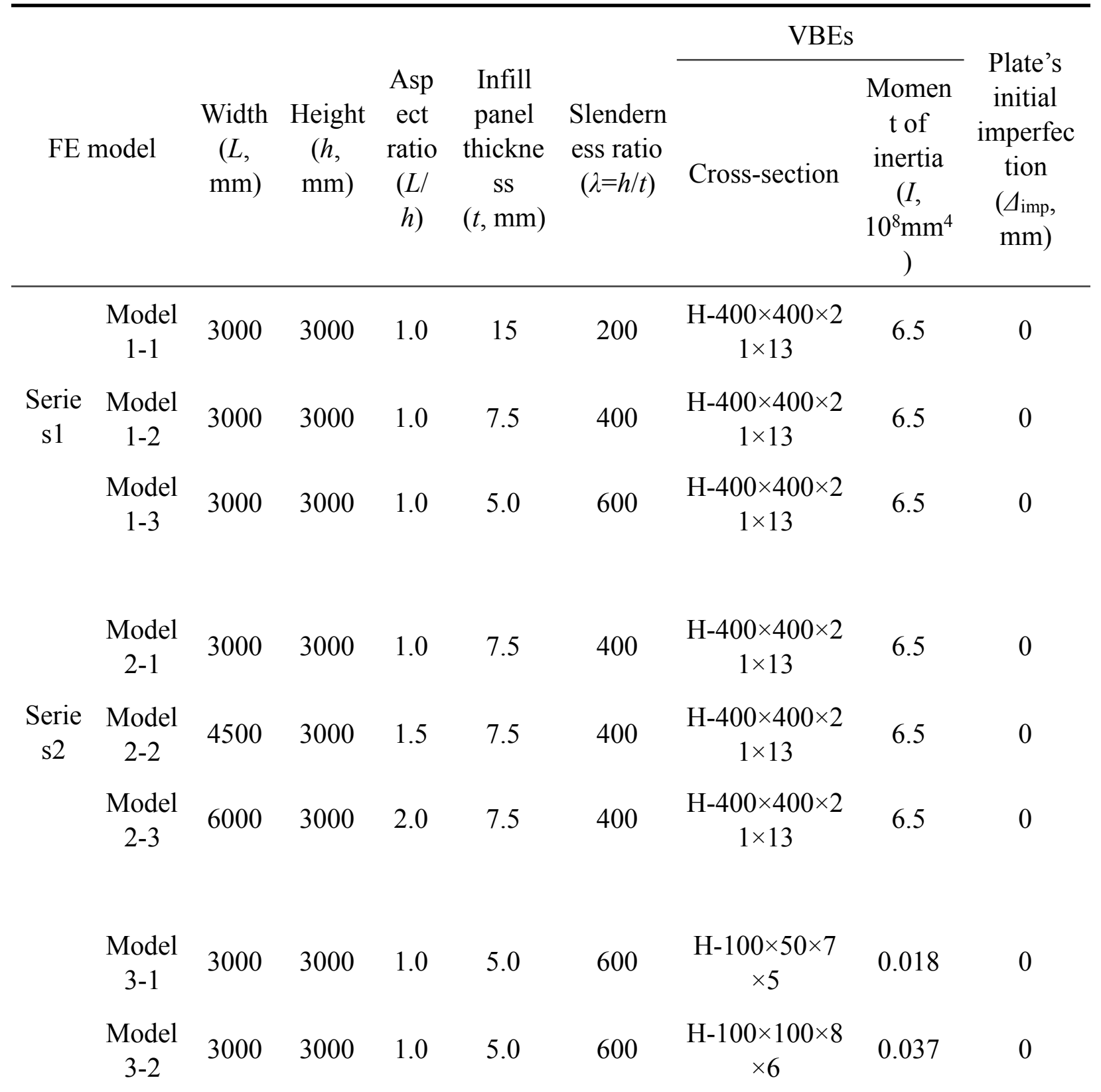




\begin{tabular}{|c|c|c|c|c|c|c|c|c|c|}
\hline & $\begin{array}{c}\text { Model } \\
3-3\end{array}$ & 3000 & 3000 & 1.0 & 5.0 & 600 & $\begin{array}{c}\mathrm{H}-150 \times 150 \times 1 \\
0 \times 7\end{array}$ & 0.16 & 0 \\
\hline \multirow{5}{*}{$\begin{array}{l}\text { Serie } \\
\text { s3 }\end{array}$} & $\begin{array}{l}\text { Model } \\
3-4\end{array}$ & 3000 & 3000 & 1.0 & 5.0 & 600 & $\begin{array}{c}\mathrm{H}-200 \times 200 \times 1 \\
2 \times 8\end{array}$ & 0.46 & 0 \\
\hline & $\begin{array}{c}\text { Model } \\
3-5\end{array}$ & 3000 & 3000 & 1.0 & 5.0 & 600 & $\begin{array}{c}\mathrm{H}-250 \times 250 \times 1 \\
4 \times 9\end{array}$ & 1.1 & 0 \\
\hline & $\begin{array}{c}\text { Model } \\
3-6\end{array}$ & 3000 & 3000 & 1.0 & 5.0 & 600 & $\begin{array}{c}\mathrm{H}-300 \times 300 \times 1 \\
5 \times 10\end{array}$ & 2.0 & 0 \\
\hline & $\begin{array}{c}\text { Model } \\
3-7\end{array}$ & 3000 & 3000 & 1.0 & 5.0 & 600 & $\begin{array}{c}\mathrm{H}-350 \times 350 \times 1 \\
9 \times 12\end{array}$ & 4.0 & 0 \\
\hline & $\begin{array}{c}\text { Model } \\
3-8\end{array}$ & 3000 & 3000 & 1.0 & 5.0 & 600 & $\begin{array}{c}\mathrm{H}-400 \times 400 \times 2 \\
1 \times 13\end{array}$ & 6.5 & 0 \\
\hline \multirow{6}{*}{$\begin{array}{l}\text { Serie } \\
\text { s4 }\end{array}$} & $\begin{array}{c}\text { Model } \\
4-1\end{array}$ & 3000 & 3000 & 1.0 & 5.0 & 600 & $\begin{array}{c}\mathrm{H}-400 \times 400 \times 2 \\
1 \times 13\end{array}$ & 6.5 & 0 \\
\hline & $\begin{array}{c}\text { Model } \\
4-2\end{array}$ & 3000 & 3000 & 1.0 & 5.0 & 600 & $\begin{array}{c}\mathrm{H}-400 \times 400 \times 2 \\
1 \times 13\end{array}$ & 6.5 & 1 \\
\hline & $\begin{array}{c}\text { Model } \\
4-3\end{array}$ & 3000 & 3000 & 1.0 & 5.0 & 600 & $\begin{array}{c}\mathrm{H}-400 \times 400 \times 2 \\
1 \times 13\end{array}$ & 6.5 & 2 \\
\hline & $\begin{array}{c}\text { Model } \\
4-4\end{array}$ & 3000 & 3000 & 1.0 & 5.0 & 600 & $\begin{array}{c}\mathrm{H}-400 \times 400 \times 2 \\
1 \times 13\end{array}$ & 6.5 & 3 \\
\hline & $\begin{array}{l}\text { Model } \\
4-5\end{array}$ & 3000 & 3000 & 1.0 & 5.0 & 600 & $\begin{array}{c}\mathrm{H}-400 \times 400 \times 2 \\
1 \times 13\end{array}$ & 6.5 & 4 \\
\hline & $\begin{array}{c}\text { Model } \\
4-6\end{array}$ & 3000 & 3000 & 1.0 & 5.0 & 600 & $\begin{array}{c}\mathrm{H}-400 \times 400 \times 2 \\
1 \times 13\end{array}$ & 6.5 & 6 \\
\hline
\end{tabular}




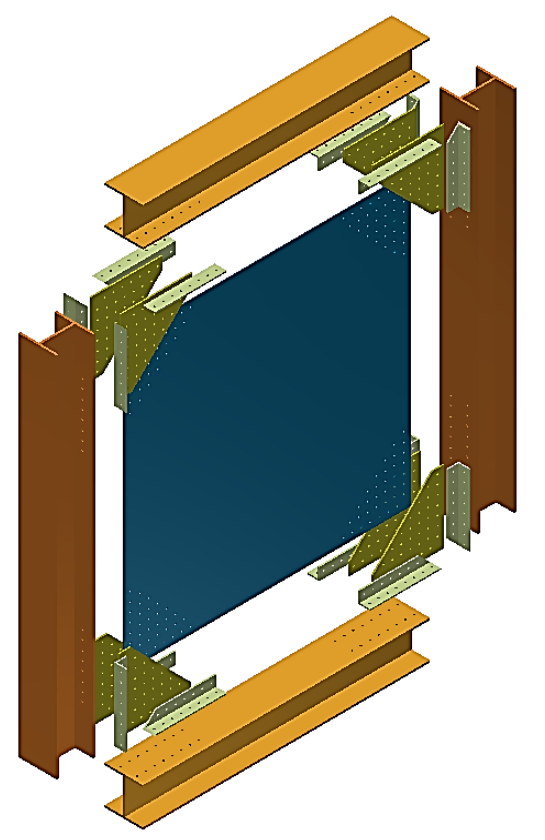

(a)

3D model

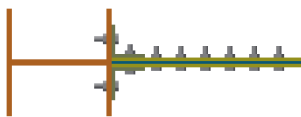

(c)

Top view

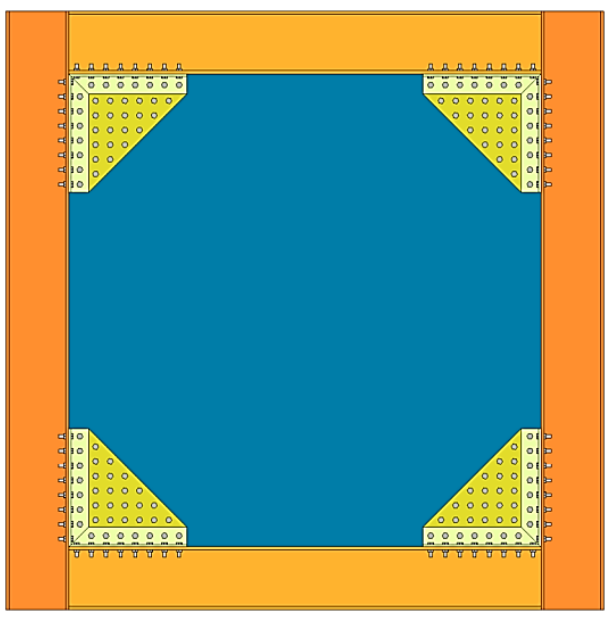

(b)

Plan view 


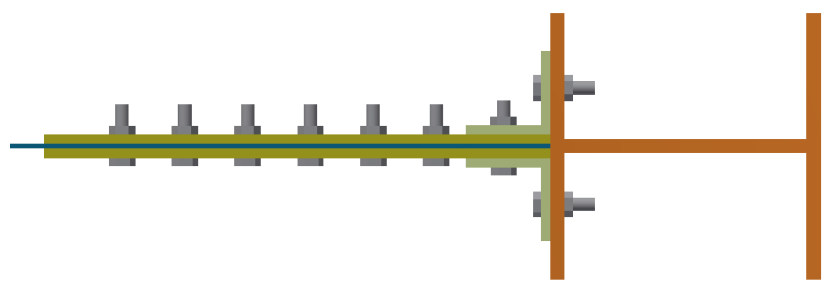

(d)

Details of connection

Fig. 1 Partially connected steel plate shear wall (SPSW)

Load

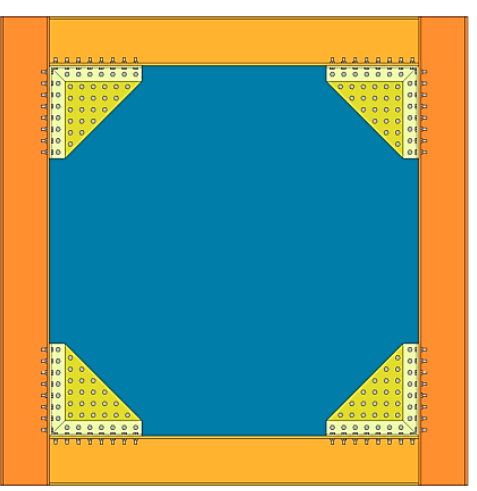

Joint
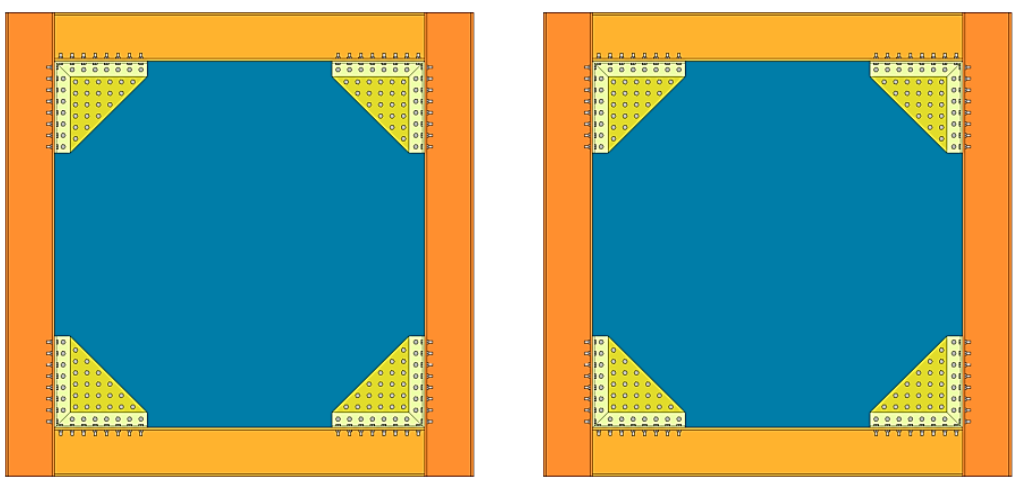

Fig. 2 Loads transfer mechanism 


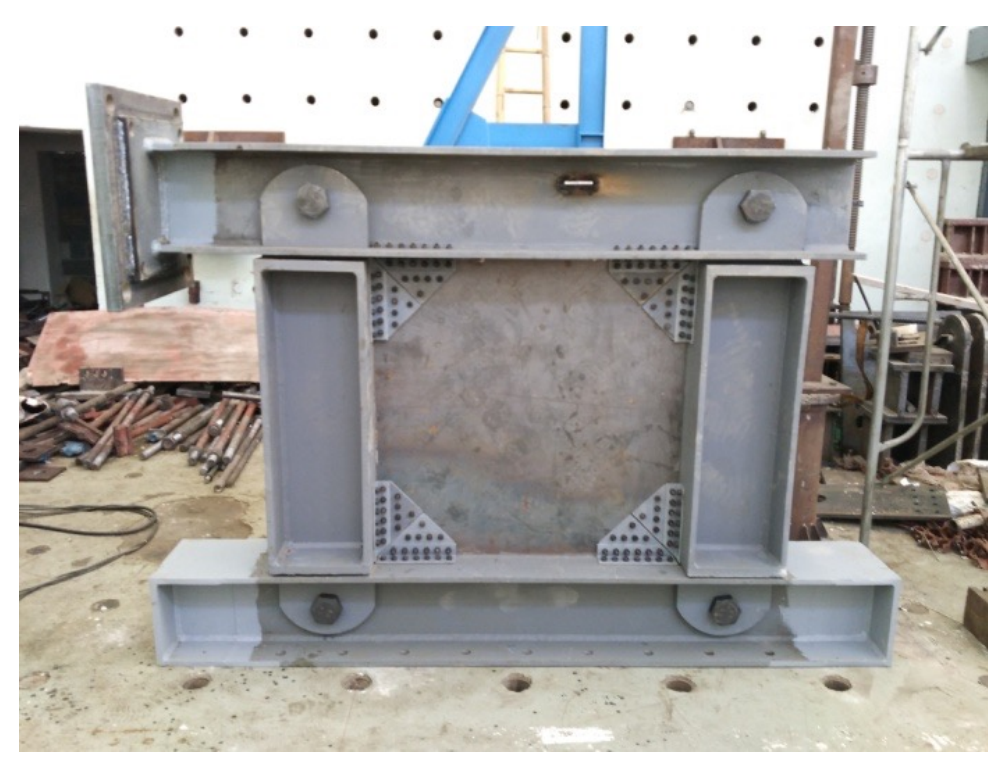

Fig. 3 Photograph of test specimen 


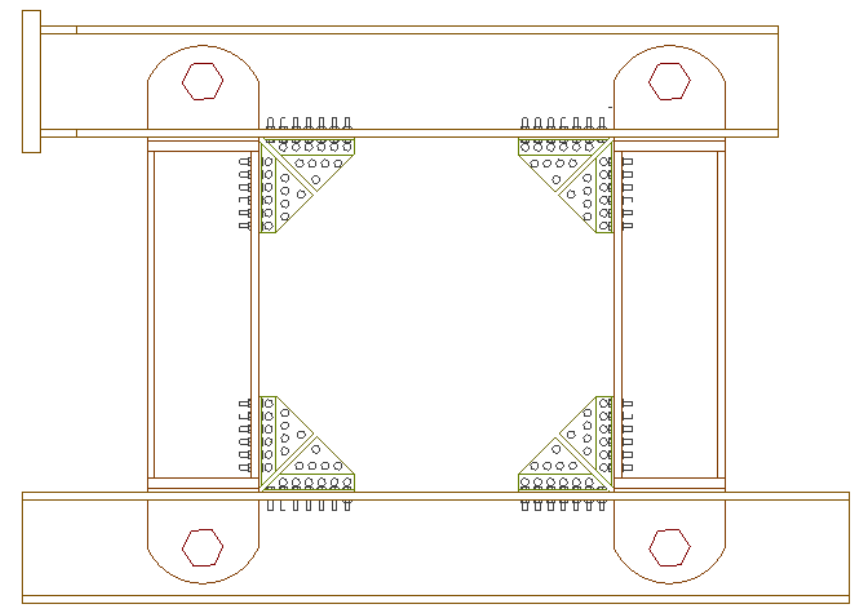

Fig. 4 Overall dimension and configuration of test specimens (mm) 


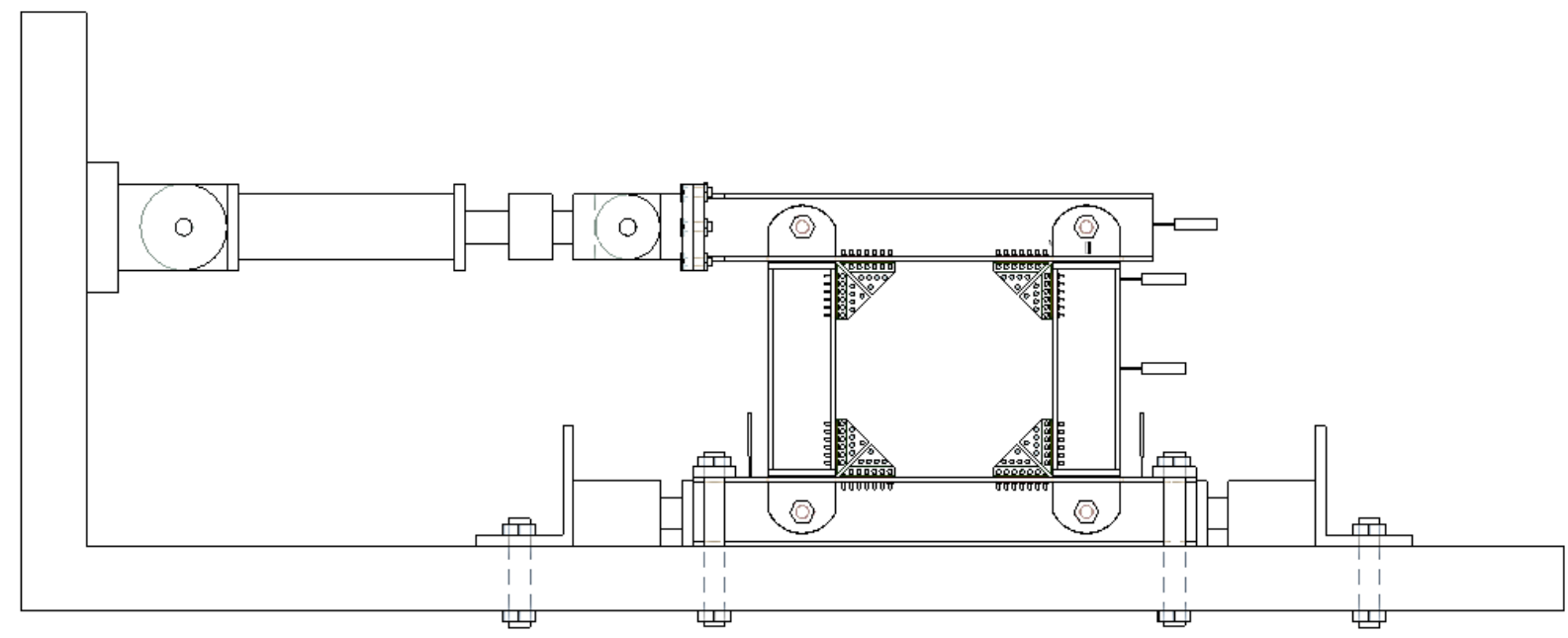

(a)

Schematic view and instrumentation plan (mm)

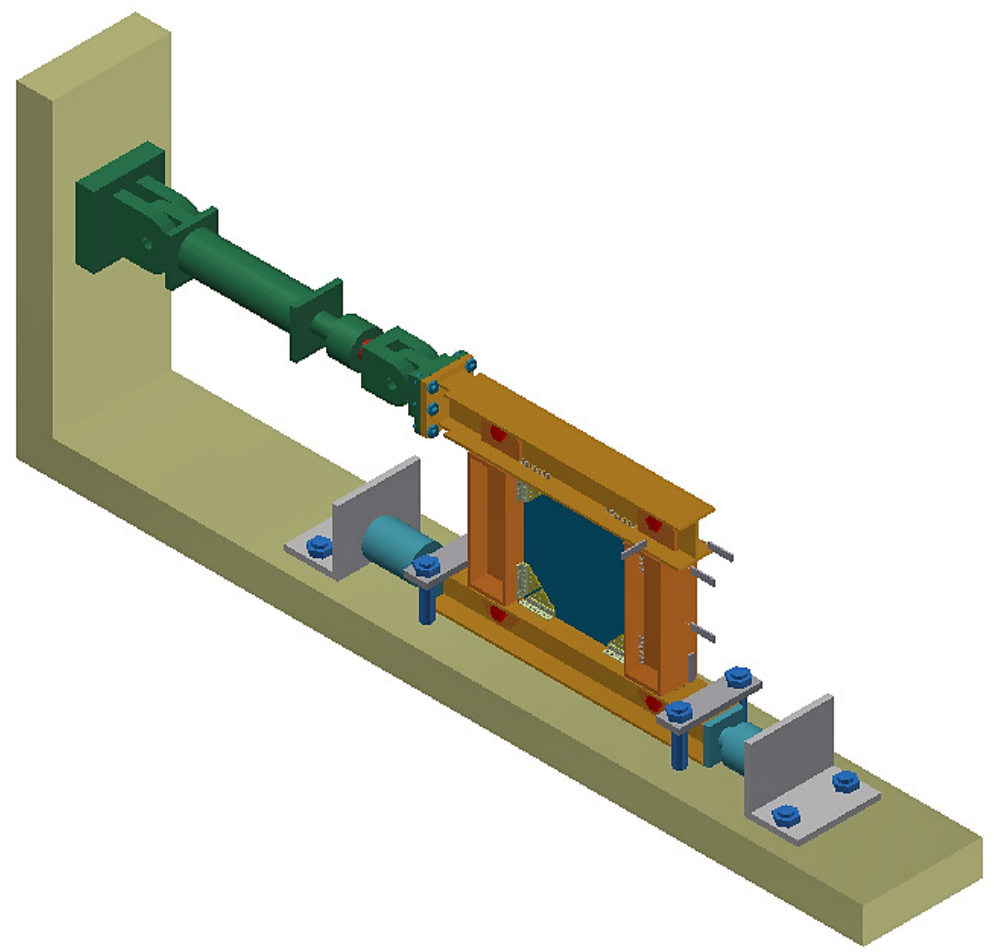

(b) Isometric view

Fig. 5 Setup of test specimen 
Fig. 6 Loading program
(a) SPSW1
(b) SPSW2

Fig. 7 Hysteresis loop for test specimens
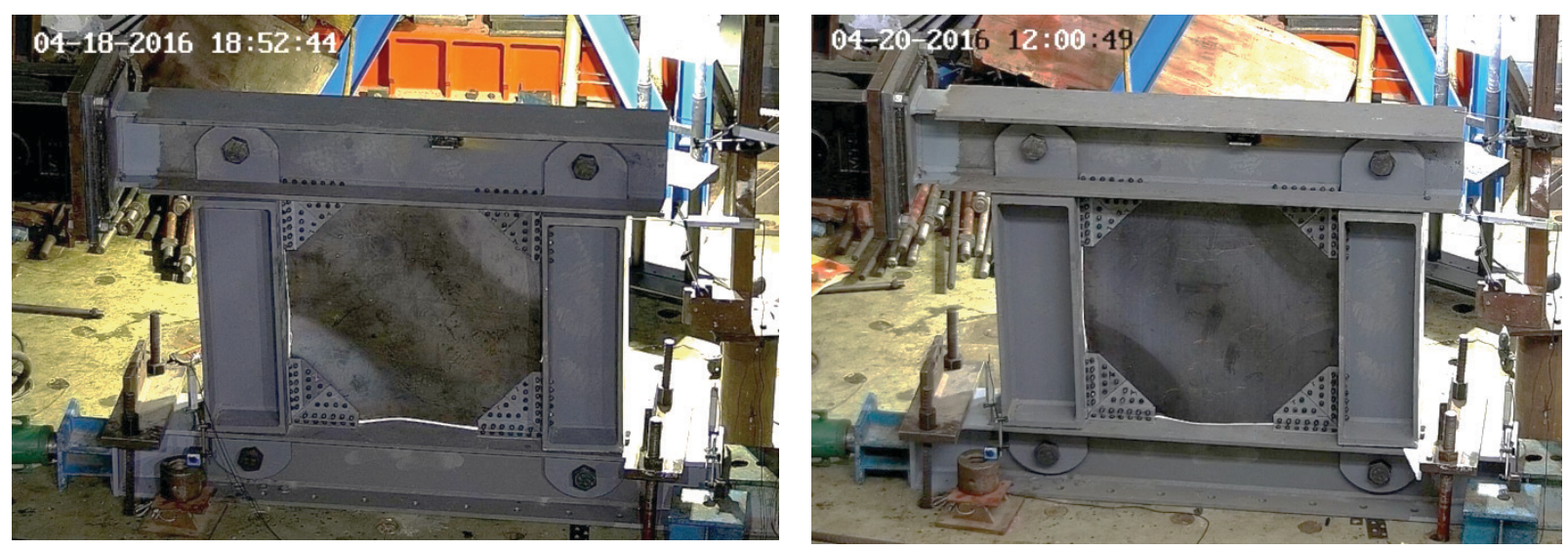

(a) Specimen SPSW1
(b) Specimen SPSW2

Fig. 8 Photographs of specimens at maximum drift ratio $4 \%$

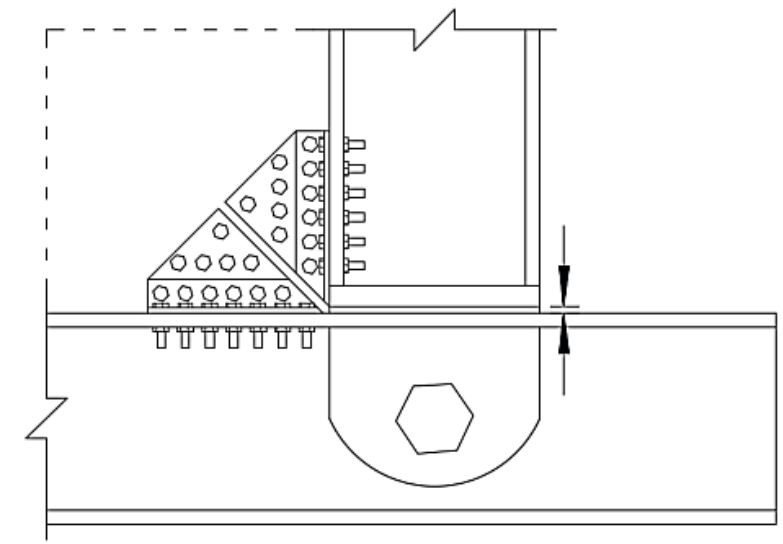

(a) Schematic diagram of joint

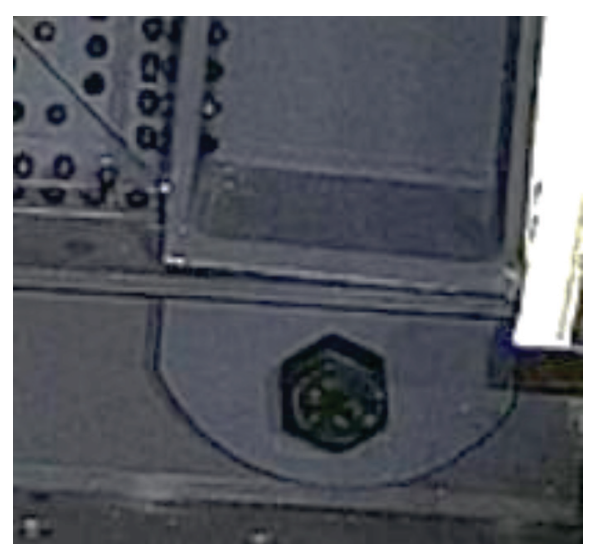

(b) Photographs of test specimens

Fig. 9 The limit rotation of hinged joint in test specimens

Fig. 10 Envelope curves of test specimens

Load, $V$ 


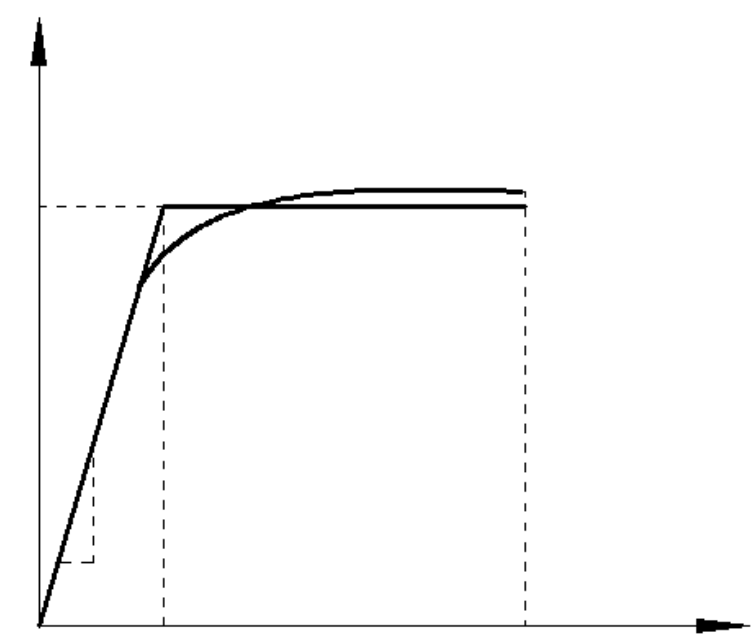

Fig. 11 General idealized relationship of shear loading versus displacement

Fig. 12 Average cumulative energy dissipation at each load step 

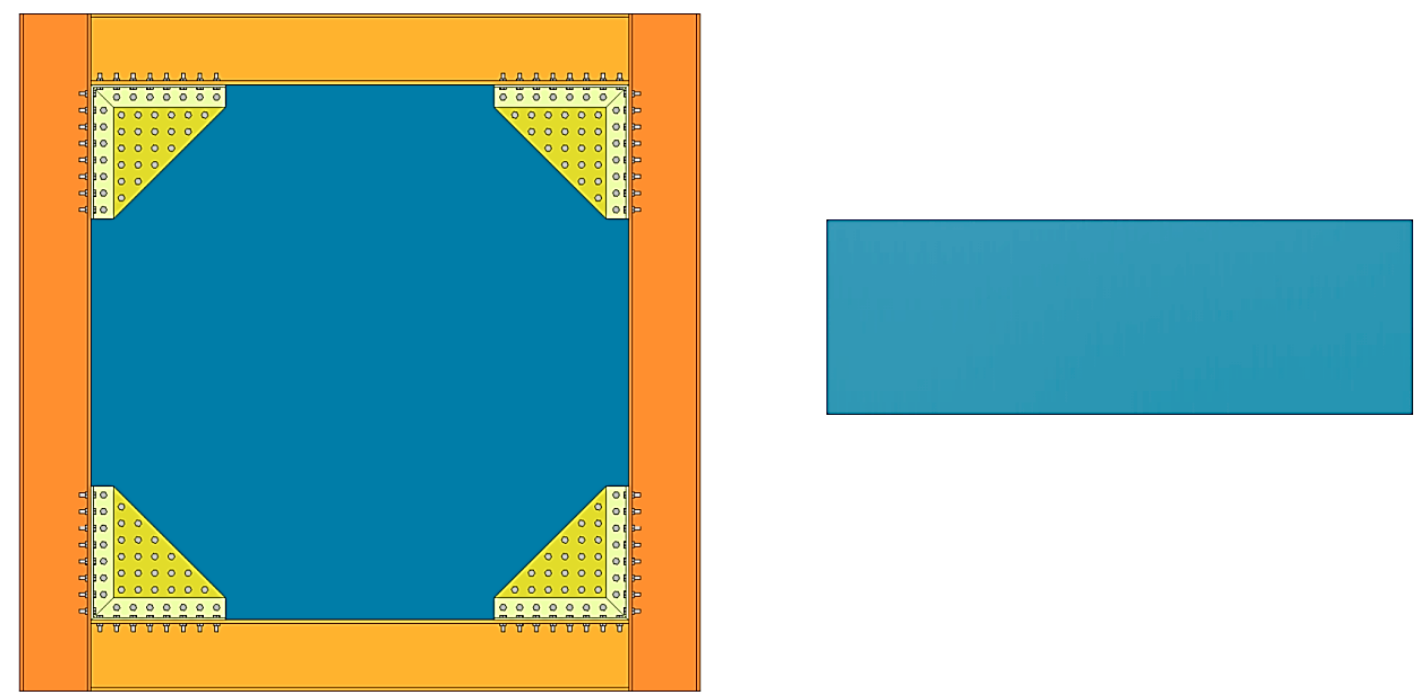

Fig. 13 Simplified mechanical model for compressive zone

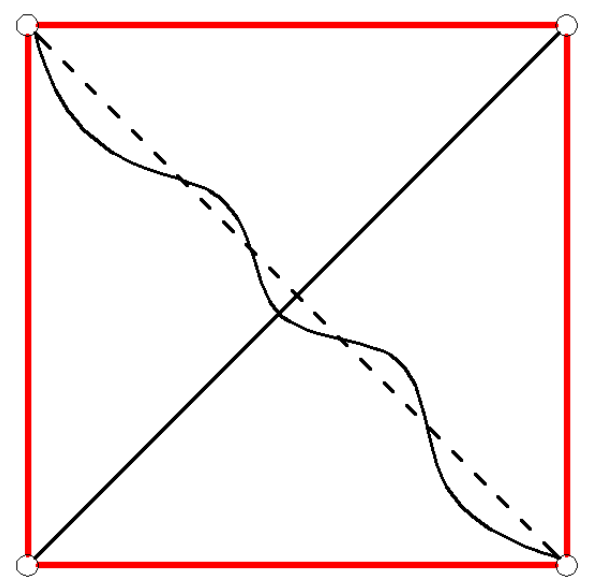

Fig. 14 Simplified mechanical model for determining shear resistance 


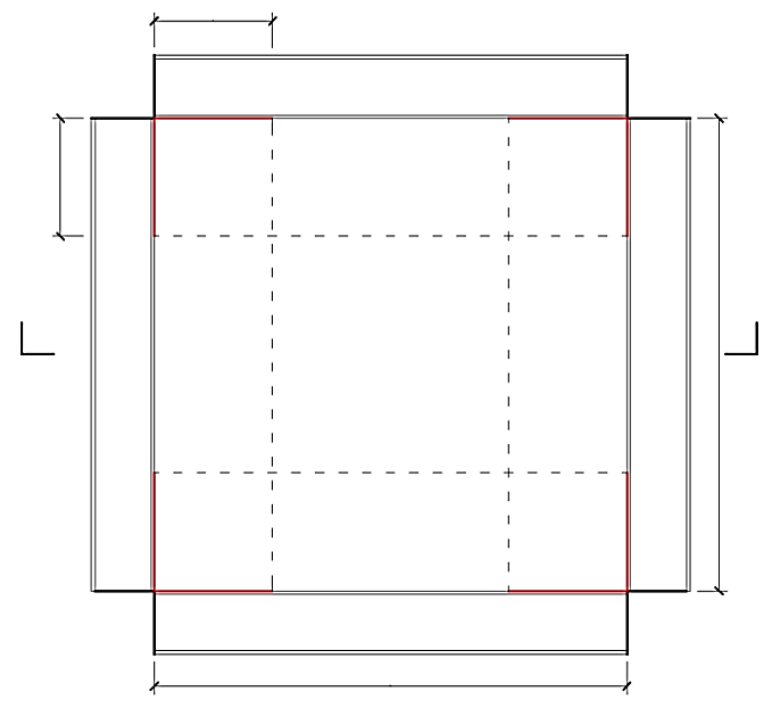

(a) Elevation view

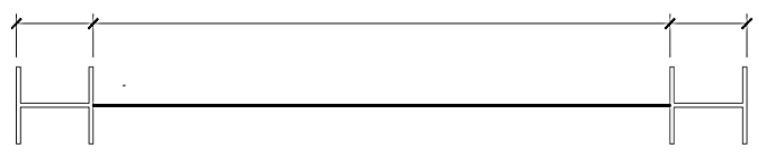

(b) A-A

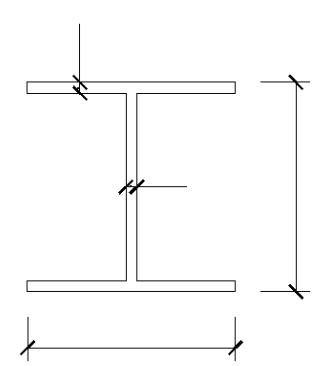

(C) H-section for HBE and VBE

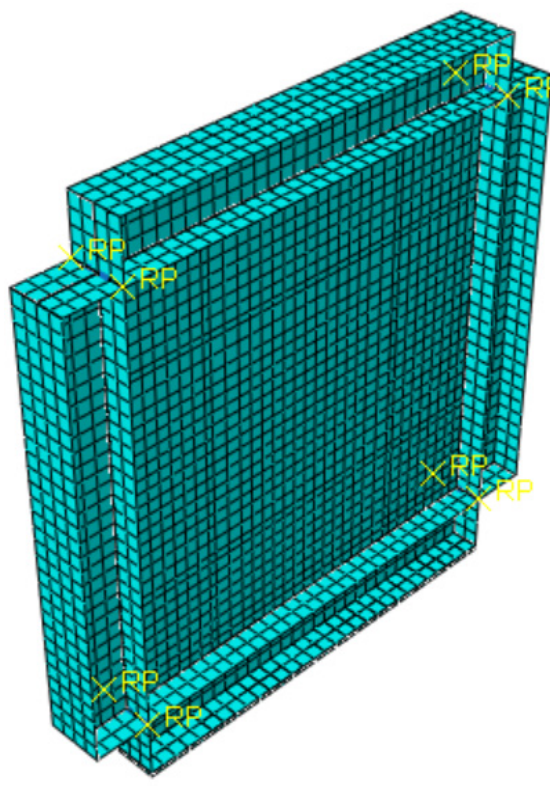

(d) FE model

Fig. 15 Details of finite element (FE) model with hinge-connected frame 


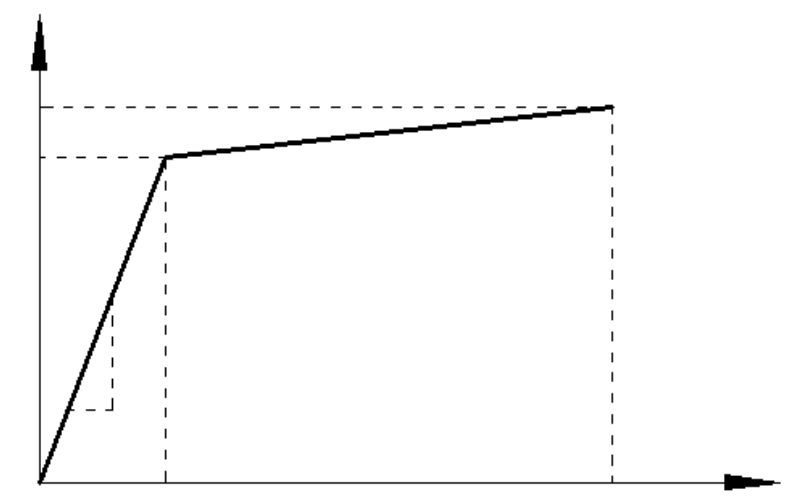

Fig. 16 Constitutive behaviours of steel
(a) SPSW 1
(b) SPSW2

Fig. 17 Comparing the results of experiment with the numerical results

(a) Hysteresis loops

(b) Envelope curves

Fig. 18 The effect of slenderness ratio 


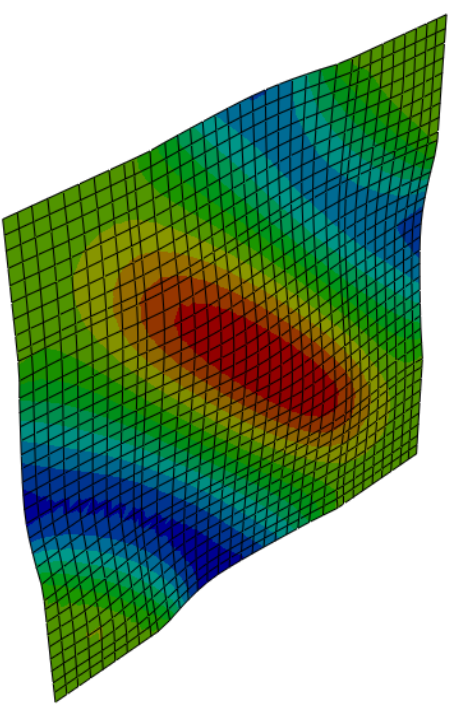

(a) $\lambda=200, t=15 \mathrm{~mm}$

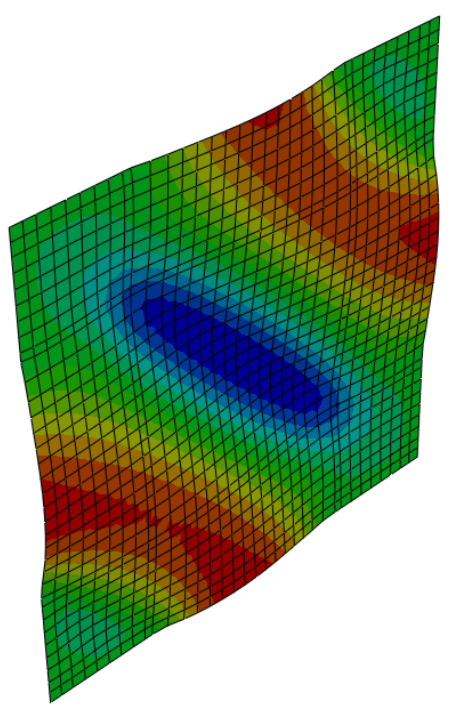

(b) $\lambda=400, t=7.5 \mathrm{~mm}$

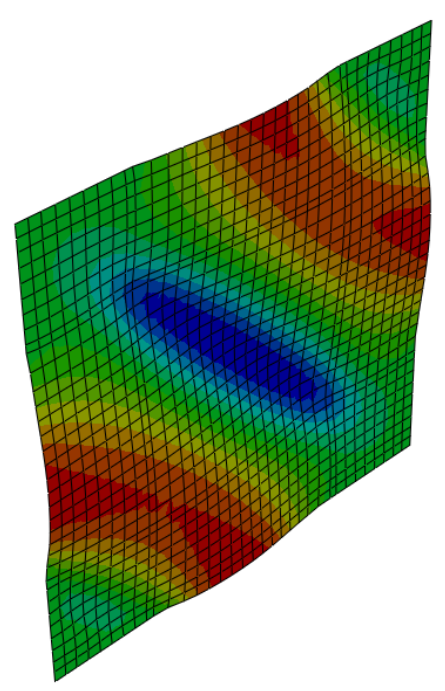

(c) $\lambda=600, t=5 \mathrm{~mm}$

Fig. 19 Out-of-plane displacement, $\Delta_{\text {out }}$, contour from series $1 \mathrm{FE}$ models

(a) Hysteresis loops

(b) Envelope curves

Fig. 20 The effect of aspect ratio 
Fig. 21 The effect of stiffness

Fig. 22 The effect of initial imperfection 